\title{
La representación de la resemantización en los diccionarios del español ${ }^{*}$
}

ISABEL SANTAMARÍA

Universidad de Alicante

\section{INTRODUCCIÓN: OBJETIVOS Y METODOLOGÍA}

En este trabajo nos vamos a centrar en la descripción de los neologismos semánticos, esto es, aquellos neologismos formados por la creación de un nuevo significado a partir de una palabra ya documentada en los repertorios lexicográficos.

Nuestro objetivo final es el estudio de los neologismos semánticos a partir de los datos recogidos en el banco de neologismos del Observatorio de Neología ${ }^{1}$, pero consideramos que el primer paso para llevar a cabo la descripción de la neología semántica es consultar las obras de referencia de la lengua española, tanto gramáticas como diccionarios, con el fin de determinar el estado de la cuestión de este fenómeno léxico.

Este mecanismo léxico-genético a partir de significados nuevos de unidades léxicas ya existentes es un aspecto que en español se ha relacionado más con el cambio semántico que con los procesos de creación léxica, centrados principalmente en los mecanismos formales. De ahí que la acuñación de significados nuevos a palabras ya existentes haya sido un proceso poco tratado en las gramáticas del español. De hecho, si acudimos a las dos gramáticas por excelencia del español: Gramática descriptiva de la lengua española (1999) en la quinta parte dedicada a la Morfología se analizan los procesos morfológicos formales de formación de palabras (derivación, composición, acortamiento, siglación, etc.). De igual modo ocurre en la Nueva Gramática de la lengua española de la Real Academia publicada en 2010, en la que tampoco se trata los fenómenos semánticos como un proceso de formación de palabras, sino que se hace referencia exclusivamente a procesos estrictamente formales. Lo mismo tiene lugar en obras dedicadas a la explicación de los procesos de formación de palabras en español como los trabajos de Almela (1999), el de Lang (1992), el de Varela (1993) o el de Alvar Ezquerra (1994). Hemos de acudir a ciertos trabajos específicos sobre neología como el de Guerrero Ramos (1995) para poder encontrar alguna referencia al cambio de sentido como proceso de creación léxica.

Esta autora distingue entre neología de forma y neología semántica, la cual define como aquel procedimiento que se produce «cuando el significante es conocido, es decir,

* Este trabajo es resultado de los estudios realizados en el Proyecto asociado «Actualización del léxico del español en la prensa de Murcia y Alicante (NEOMA) dirigido por la profesora María del Carmen Sánchez Manzanares dentro de la red NEOROC (Red de Neología del Español peninsular).

${ }^{1}$ Se puede visitar el banco de datos de dicho observatorio, BOBNEO, en la siguiente dirección: www.iula.upf. 
cuando no hay un elemento formal nuevo, sino que la carga semántica es nueva» (1995: 39). Guerrero enumera tres procedimientos o recursos para la creación de nuevos sentidos:

1) Formación de lexías complejas, casi siempre formado por un sustantivo acompañado de adjetivo o sintagma preposicional como auditoría ambiental.

2) Neología por conversión, la cual consiste en el cambio de categoría gramatical del lexema: conversión de sintagma preposicional a adjetivo (aumento de salario $>$ salarial); sustantivación del adjetivo por elipsis del sustantivo (empresa constructora $>$ constructora); adjetivización de sustantivo (obra cumbre; partido bisagra); adverbialización del adjetivo («se ha portado genial») y finalmente, adverbialización de nombre («pasarlo pipa o bomba»).

3) La metáfora, que consiste en una reducción del contenido semántico en comprensión y presenta una mayor extensión de aplicación. Solo conserva una parte de los semas. Por ejemplo, cumbre pierde el sema 'pico de montaña' y conserva el de 'parte más alta' ${ }^{2}$.

Por tanto, debido a la falta de tratamiento de este proceso en las obras gramaticales y especializadas en el tema en español, nos centraremos en la caracterización que hacen los diccionarios de la lengua española, fijándonos en las marcas valorativas de uso que utilizan para indicar las relaciones semánticas entre los diferentes significados de una entrada o para indicar el significado nuevo en relación con el antiguo. Así, nos proponemos analizar cómo los diccionarios han tratado el grupo léxico caracterizado por las etiquetas conocidas como marcas de transición semántica: especialmente, por extensión, por analogía y figurado.

El método empleado para la consecución de estos fines será el estudio directo de los diccionarios y el cotejo de estos a partir de un número de unidades léxicas marcadas semánticamente. Para llevar a cabo este análisis hemos tomado como punto de partida el diccionario académico [DRAE] en su edición digital de 2001 que permite realizar búsquedas específicas y el diccionario de María Moliner [DUE], también en su edición digital del $2008^{3}$. Partiendo de las entradas obtenidas se ha llevado a cabo la búsqueda y la comparación con el Diccionario del Español Actual [DEA] (1999) y el Diccionario de la lengua española [LEMA] (2001). Con los resultados alcanzados hemos analizado unas cuantas entradas de cada una de estas marcas con el fin de determinar los procesos más frecuentes que se utilizan para introducir nuevos significados en los diccionarios del español.

\section{NEOLOGÍA SEMÁNTICA: DEFINICIÓN Y DELIMITACIÓN}

Antes de empezar con el análisis consideramos necesario definir y delimitar el concepto de neologismo semántico en el que nos basamos.

Como indica Carmen Varó y otros (2009: 188) parece existir un amplio consenso entre los estudiosos de la neología (Bastuji 1974, Matore 1952, Rey 1976), cuando se

${ }^{2}$ Para este trabajo, y teniendo en cuenta las directrices del Proyecto del que formamos parte, solo tendremos en cuenta el tercer grupo de neologismos formados por metáfora, ya que los otros se analizarán como compuesto o como casos de conversión sintáctica.

${ }^{3}$ Dado que el DUE no incluye estas marcas en la lista de abreviaturas, las búsquedas de las entradas con estas valoraciones se ha hecho a través de la 'busqueda avanzada' a partir de la definición. 
trata de aceptar que esta hace referencia al proceso de creación de nuevas unidades léxicas, mientras que el neologismo es el resultado del proceso, esto es, el producto, la nueva unidad léxica ${ }^{4}$.

Así pues, el neologismo puede ser una unidad léxica de creación reciente en su significante y su significado (por ejemplo, eurozona, chatear), una unidad léxica de creación reciente solo en su significante (por ejemplo, ecoauditoría, a partir de 'auditoría'), una unidad léxica recientemente tomada de otra lengua (por ejemplo, blog, e-book), o todo significado o acepción nueva para un significante ya existente (por ejemplo, navegar, nube). Por tanto, entre las unidades léxicas registradas como neologismos es posible diferenciar, según el procedimiento o el recurso utilizado ${ }^{5}$, las que se manifiestan bajo la forma de un significante no registrado aún en la lengua y las que se manifiestan bajo la forma de un significante ya existente, resultando de esta distinción, la delimitación entre la denominada neología formal o de forma y la neología semántica o neología de sentido ${ }^{6}$.

Situándonos en la neología semántica, objeto de estudio en este trabajo, podemos diferenciar distintos modos para la creación de «un nuevo sentido para una lexía cuyo significante ya existía con otro significado» (Sablayrolles 1997), modos bastante relacionados con las clasificaciones establecidas para el cambio semántico, desde la tipología clásica de Bloomfield (1933) que diferenciaba entre restricción de significado, ampliación de significado, metáfora, metonimia, sinécdoque, litote, hipérbole, degeneración y elevación, u otras más recientes como la de Ullman (1957) o Blank (1999). En las tipologías de neología semántica más recientes se puede observar cómo los procesos son los mismos ${ }^{7}$.

Para este trabajo nos basamos en la propuesta de Cabré (2009: 34-36) que plantea una tabla de clasificación multivariante de los neologismos, basada en cuatro criterios principales: 1) Variación gráfica/fonológica, en los casos que no se trate de una variante ortográfica; 2) Vía o proceso final por el que el neologismo entra en el uso lingüístico: creación,

${ }^{4}$ Una revisión de las definiciones de los términos neología y neologismo que se encuentran en diccionarios de lengua, diccionarios de lingüística, obras lexicográficas, de terminología lingüística y estudios monográficos de los más representativos investigadores de este fenómeno figura en Díaz Hormigo (2008: 9-13), donde queda claro que este fenómeno queda limitado a nivel léxico y no a otros fenómenos lingüísticos nuevos en otros niveles de análisis y descripción de las lenguas.

${ }^{5}$ Para la caracterización de estos tipos de neología y las características de los neologismos que resultan del establecimiento de esta tipología, se puede consultar Cabré (1993: 446-448) y Cabré et al. (2002: 161-164).

${ }^{6}$ Por otra parte, si se emplean otros criterios, como el ámbito de uso, se diferencia entre la neología léxica de la lengua común (la neología general o neología propiamente dicha) y la neología léxica de las lenguas de especialidad (la neología especializada, terminológica o neonimia) (Rondeau 1984). Si la delimitación se realiza tomando como base su origen y la naturaleza del proceso de creación, se diferencia entre los tipos de la neología espontánea y la neología planificada. Por su función o finalidad, la neología puede ser denominativa o referencial, pues puede consistir en la creación, espontánea o planificada, de nuevas unidades léxicas para la denominación de nuevos conceptos, objetos o realidades, o bien estilistica o expresiva, si lo que se pretende con la nueva creación léxica es introducir matices subjetivos o nuevas formas expresivas u originales en la comunicación. Como vemos los neologismos se pueden clasificar según diversos criterios (sistema lingüístico, función, tipo de proceso, etc.) y de acuerdo con ello han aparecido diversas tipologías, entre las que destaca las de Corbeil (1971), Deroy (1971) y Guilbert (1975), recogidas en el artículo de Sablayrolles (1997).

${ }^{7}$ Véase Guilbert (1975), Sabrayrolles (1997); Cabré (2009). 
formación, préstamo; 3) Estructura interna: simple/construida; 4) Agente neológico: neologismo planificado/espontáneo.

Según el criterio de incorporación del neologismo al uso lingüístico, considera, entre otros, el procedimiento de cambio, en el que la autora distingue entre cambio gramatical y resemantización. A continuación, representamos los subtipos dados para cada uno de ellos (Cabré 2009: 35).

\begin{tabular}{|l|l|}
\hline \multicolumn{2}{|c|}{ PROCEDIMIENTOS DE CAMBIO } \\
\hline \multirow{2}{*}{ TIPO } & SUPTIPO \\
\hline \multirow{2}{*}{ CAMBIO GRAMATICAL } & Cambio de categoría gramatical \\
\cline { 2 - 2 } & Cambio de subcategorización \\
\hline \multirow{2}{*}{ RESEMANTIZACIÓN } & Reducción de significado \\
\cline { 2 - 2 } & Ampliación de significado \\
\cline { 2 - 2 } & Cambio de significado \\
\hline
\end{tabular}

Tabla 1. Procedimientos de cambio según Cabré (2009)

Dejando de lado los cambios de significado en palabras ya existentes producidos por cambios gramaticales (de categoría gramatical, de género o de número) ${ }^{8}$, nos centraremos en los cambios producidos por extensión, reducción o cambio de significado, los cuales tienen mucho que ver con la polisemia léxica; esto es, los múltiples semas o sentidos de una palabra y cómo esas modificaciones de significado se representan en los diccionarios.

Según el protocolo establecido por el Observatorio de Neología (2004: 17) en el que nos basamos en este estudio, se considera neologismo semántico todo aquel neologismo formado por una modificación del significado de una base léxica. Veamos un ejemplo:

Según el Diccionario de la Real Academia, un buscador es 'que busca'; pero en el siguiente contexto:

Un gran problema que tienen todos los *buscadores*, y Google el primero de todos, es el spam, la gente consigue meterle ahí unas webs que no sirven de nada y que encontramos en las búsquedas,

la palabra buscador no hace referencia al significado que recoge el diccionario, sino a un concepto nuevo:

Herramienta de búsqueda consistente en una base de datos de páginas web indexadas automáticamente, que permite que el usuario haga consultas a partir de una o más palabras que figuran en los documentos indexados ${ }^{9}$.

Este ejemplo sirve para explicar que cuando una sociedad tiene la necesidad de designar una nueva realidad no siempre crea una unidad formalmente nueva, sino que puede hacerlo dando un nuevo significado a una unidad léxica ya existente.

\footnotetext{
${ }^{8}$ Consideramos que los casos en los que se produce un cambio de categoría gramatical o la lexicalización de alguna forma flexiva son procesos sintácticos más que semánticos.

${ }^{9}$ Definición extraída del Diccionario de neologismos on line [www.upf.edu].
} 
También se considera otro grupo de neologismos semánticos, los nombres propios (de persona o de marca registrada) que pasan a ser utilizados como nombres comunes, ya que al perder las características de nombre propio, estos modifican su significado y denotan un conjunto o una clase de individuos o entidades que tienen unas características comunes (Bosque 1999: 5). Es el caso de nombres como barbie en contextos como el siguiente:

Desde mi infancia siempre he coleccionado barbies y siempre he querido ser como una barbie, por ello el papel me ha venido como anillo al dedo [BOBNEO, LV, 05/10/2008],

donde barbie deja de ser un nombre de una muñeca para designar un tipo de mujer con determinadas características físicas: rubia, esbelta, alta, etc.

$\mathrm{O}$ nombres de persona que pasan a designar una clase. En el siguiente ejemplo, el creador de una técnica de entrenamiento físico, Joseph Pilates, ha dado nombre al método:

El método pilates enseña a respirar para facilitar la descarga muscular [BOBNEO, EP, 11/10/2007]

Antes de iniciar el análisis de los neologismos semánticos obtenidos en BOB$\mathrm{NEO}^{10}$, vamos a analizar la caracterización que hacen los repertorios lexicográficos cuando quieren indicar un cambio o modificación de sentido. Como los diccionarios no incluyen una explicación sobre el tratamiento de los significados nuevos en los artículos lexicográficos, nos tendremos que fijar en el uso de las marcas valorativas que indican la relación del significado nuevo con el antiguo: marcas de transición semántica. En lo que sigue nos fijaremos en cómo aparecen representados en los diccionarios de lengua española los dos tipos de neologismos semánticos diferenciados así como las marcas empleadas para indicar los cambios de significado.

\section{LAS MARCAS DE TRANSICIÓN SEMÁNTICA}

No voy a insistir en la controversia generada por la presencia de estas marcas en los diccionarios de uso para lo que me remito a la literatura especializada, especialmente a los trabajos de De Hoyos (1999-2000), de González Pérez (2000-2001) y el reciente estudio de prospección bibliográfica realizado por Martínez Gajardo (2011) donde describe la postura de distintos especialistas a la hora de incluir la marca de transición semántica figurado en los diccionarios de uso del español. Como indica esta autora (2011: 221), el tratamiento de la polisemia léxica en el diccionario sigue siendo un problema debido a la relación que se establece entre sentido recto y sentido figurado de una unidad léxica polisémica.

Lo cierto es que desde la aparición del trabajo de De Hoyos (1999-2000), el diccionario académico y los diccionarios de uso del español han suprimido de sus páginas estas marcas, especialmente la que hace referencia al sentido figurado, debido al tipo de información que designan con respecto de la acepción y la relación que establecen

\footnotetext{
${ }^{10}$ Dejamos para un trabajo posterior el análisis de los procesos que determinan la creación de nuevos significados en palabras ya existentes.
} 
con el sentido recto de una unidad léxica polisémica. No obstante, todavía se encuentran testimonios de las mismas como veremos entre las páginas de las obras lexicográficas. Veamos algunas de estas posturas.

Para Fajardo (1996-1997), la función principal de la marcación en el diccionario es caracterizar a un elemento léxico, señalando sus restricciones y condiciones de uso. Este autor deja fuera del sistema de marcas las indicaciones complementarias como transiciones semánticas o categoriales, puesto que no considera que expresen restricciones o condiciones de uso de la unidad léxica. Con ello, para Fajardo, figurado no sería una marca, sino solamente una indicación complementaria expresada a través de una fórmula fija: fig. Lo mismo se podría decir de otras etiquetas usadas tradicionalmente en los diccionarios del español como especialmente, por extensión,por analogía...

Seco (1978) diferencia dos tipos de información dentro del artículo lexicográfico: la información de primer enunciado, aquella información referida a la unidad léxica en cuanto signo, frente a la de segundo enunciado, referida a su contenido. Así, en el primer grupo aparecería información sobre la etimología y la categoría gramatical, su vigencia, sus límites geográficos, el campo del saber o actividad a la que pertenece, sus niveles de uso, sus particularidades de «colocación» respecto de contextos reales de uso o locuciones, y la explicación de transiciones semánticas y categoriales en acepciones secundarias. Esta última categoría de información de primer enunciado mencionada por el autor es la siguiente: «f) explicación de las transiciones semánticas, por medio de abreviaturas como fig., por ext., irón.» ${ }^{11}$ (Seco 1978: 16). El hecho de incluir esta información dentro del primer enunciado, siguiendo a Martínez Gajardo, no nos parece lo más adecuado, pues consideramos que esta información no es un aspecto de la unidad léxica en cuanto signo, sino parte del contenido de esta, puesto que afecta directamente a su significado.

De Hoyos (1999-2000) manifiesta en su trabajo que la marca de transición semántica figurado debido a su propio carácter; esto es, marcar la evolución interna del significado (sentidos propios, primeros, rectos frente a sentidos impropios, secundarios, derivados, figurados), interesa en una obra diacrónica corno el diccionario histórico, pero no debe aparecer en los diccionarios de uso, donde se necesita más información de uso o pragmática que ayude a resolver las dudas planteadas por los usuarios de estas obras lexicográficas. El autor considera que estamos ante una marca que aporta información adicional con respecto a la acepción y por tanto, no es necesaria.

Borràs y Torner (2006), tras el estudio de un corpus de zoónimos en el DRAE 1992, consideran que:

la marca fig. tal como se emplea en el DRAE (1992) no es en rigor una marca diacrónica, sino que se trata de una marca que indica el modo como debe ser leída la definición o, en otros términos, el modo como se emplea la palabra en esa acepción [...] además de semántica y de uso (uso predicativo), una marca cultural, lo cual

\footnotetext{
${ }^{11}$ Dejamos fuera la marca iron. referente al uso irónico de una voz, puesto que ya la tratamos en
} un trabajo anterior (Santamaría 2011). 
supera las fronteras de la información meramente diacrónica o etimológica (Borràs y Torner 2006: 37-38).

Por consiguiente, cada unidad léxica polisémica establece una red semántica que se estructura como una categoría radial y «los contenidos constitutivos de una red semántica polisémica no se generan por efecto del contexto, sino que se encuentran instanciados en la memoria semántica de largo plazo (= "léxico mental"), es decir, los significados que la constituyen están convencionalizados» (Rojas 2010: 17). El trabajo de Borràs y Torner (2006) finaliza con el siguiente planteamiento:

\begin{abstract}
[...] no creemos que ni los errores observados en la praxis ni las dificultades inherentes que supone la marcación de los sentidos figurados justifiquen sin más su supresión. De otro modo, el diccionario no puede reflejar adecuadamente las relaciones que las entradas léxicas mantienen entre sí, que contemplan necesariamente la metáfora sincrónica en el sentido propuesto por van $\operatorname{der} \operatorname{Meer}^{12}$ (2006: 41).
\end{abstract}

Recapitulando lo que hemos expuesto hasta aquí, las marcas de transposición semántica, y especialmente la marca fig. ${ }^{13}$, han sido descritas en la literatura especializada como unas etiquetas que ofrecen información diacrónica o etimológica (bajo la oposición primaria/derivada), de tipo estilística para otros (bajo la oposición sentido recto/sentido figurado) y de indicación de uso predicativo para los últimos (bajo la oposición uso extensional o denotativo/ uso intensional o predicativo) (Martínez Gajardo 2001). Aún así, siguen estando presentes en los diccionarios del español como veremos.

\title{
3.1. Las marcas de transición semántica en los diccionarios del español
}

Este tipo de marcación supone una serie de problemas teóricos y prácticos que se traducen en una aplicación irregular de marcas como figurado, por extensión, por traslación, metafórico, metonímico, por antonomasia, particularmente, por excelencia, entre otras. La propia concepción de estas marcas, entendidas como indicadoras de una modificación o desplazamiento semántico a partir de un significado o acepción de significado de la entrada, hace muy compleja su asignación, debido precisamente a la dificultad de determinar los mecanismos semánticos — metáfora, metonimia, sinécdoque, generalización, especialización, etc.— que están detrás del significado desplazado de una unidad léxica, las cuales no se especifican o no se diferencian en los dicciona-

${ }^{12}$ Van der Meer (1999) defiende que la metáfora no debe ir siempre ligada a la diacronía, sino que se basa en una concepción sincrónica de la metáfora; esto es, el significado de las voces en la mente del hablante es como una red, y no como una serie de acepciones. Al utilizar la metáfora se focalizan o se potencian unos rasgos de significado más que otros, pero no se pierde el significado.

${ }_{13}$ Martínez Gajardo (2011: 230) indica que «la relación que se establece entre las distintas acepciones de una unidad léxica polisémica es central para comprender las actitudes que genera la marca de sentido figurado entre representantes de cada paradigma o escuela lingüística». Así, para Borràs y Torner (2006), más cercanos al enfoque cognitivista de la polisemia, si se suprime la marca fig. se deja de expresar aspectos relevantes del significado de la unidad. En cambio, para otros autores, como Pérez Castro (2002), pertenecientes a la escuela estructuralista norteamericana, la marca es completamente innecesaria, ya que las acepciones de sentido figurado expresan solo el «significado efectivo» de las unidades léxicas; esto es, [...] «los usos y sentidos figurados ni son nunca gratuitos ni consisten en una desviación respecto del significado propio: lo que cambia, cuando algo cambia, es la naturaleza del referente aludido, o el ámbito de uso, no el contenido semántico esencial» (2002: 128). 
rios (Porto Dapena 2002: 254) ${ }^{14}$. Por ello, la marca en sentido figurado suele funcionar, muchas veces, como hiperónimo de las demás marcas (Bajo Pérez 2000: 25 y Porto Dapena 2002: 254), convirtiéndose, así, en una de las marcas más difundidas y, en consecuencia, una de las más estudiadas, aunque es posible encontrar unidades marcadas con otras etiquetas que implican un desplazamiento semántico como por antonomasia, por extensión o por analogía.

Si hacemos una revisión de algunos de las obras lexicográficas más representativas del español se observa que se sigue aplicando este tipo de marcación, pero el examen revela también que no existe un procedimiento sistemático dentro de una misma obra o respecto a una misma unidad, si comparamos obras lexicográficas distintas.

En el DRAE- $20011^{15}$ se producen cambios sustanciales con respecto a las ediciones anteriores, especialmente la edición del 92. En el apartado de Advertencias no se hace mención alguna a esta marca. Solo en el apartado 6.3. que trata las notas de uso se incluye como uno de los ejemplos:

La información expresada mediante las marcas, generalmente abreviadas, que encabezan una acepción, puede ser completada o matizada por una o más notas situadas al final del texto definidor. P. ej.: trallazo. m. [...] $\|$ 3. Golpe o ruido violentos. U. t. en sent. fig. [...]

No obstante, cuando consultamos las abreviaturas y marcas empleadas en el modo de 'consulta avanzada' nos encontramos con la acotación transición semántica bajo la cual se incluye la antífrasis ${ }^{16}$ (3), el sentido figurado (295) y la antonomasia (90).

friolero, ra. 2. f. Cosa de poca monta o de poca importancia. U. m. c. antifrasis amurallar.1. tr. Rodear de murallas. U. t. en sent. fig.

gas.5. m. pl. por antonom. Gases que se producen en el aparato digestivo.

Frente a las más de 17.000 acepciones marcadas como fig. en el DRAE- $1992^{17}$, en la vigésimo segunda edición del DRAE, la marca solo ha quedado en 295, siempre bajo la fórmula «Ú.t. en sent fig.» o similar, que indica que en esa acepción de la unidad léxica, además de en sentido recto, es posible utilizarla en sentido figurado, tal y como se define este adjetivo en el DRAE ${ }^{18}$.

${ }^{14}$ Por lo expuesto, este tipo de marcación ha sido siempre el blanco de críticas por parte de lexicógrafos y lingüistas (Hoyos 1999-2000; Bajo Pérez 2000: 25; González Pérez 2000-2001: 83 y sigs.; Porto Dapena 2002: 256; Battaner 2010).

${ }^{15}$ Para conocer cómo ha ido evolucionando la marca figurado a lo largo de la tradición lexicográfica académica desde Autoridades hasta el DRAE-1992, se recomienda el estudio de De Hoyos (1999-2000).

${ }^{16}$ Según el DRAE, antífrasis es una «Figura que consiste en designar personas o cosas con voces que signifiquen lo contrario de lo que se debiera decir'. En este caso, aunque hay un desplazamiento hacia un significado contrario, no lo incluímos en nuestro estudio.

${ }^{17}$ Información extraída a partir del trabajo de De Hoyos (1999-2000). Además este autor muestra en su estudio como muchas de estas acepciones que antes aparecían con la marca fig., aparecen ahora con la marca coloq. (coloquial). Ej.: cerdo. (...). 3. m. coloq. puerco (// hombre sucio). U. t. c. adj. 4. m. coloq. puerco (// hombre grosero). U. t. c. adj. 5. m. coloq. puerco (// hombre ruin). U. t. c. adj. (DRAE 2001).

${ }^{18}$ Véase página 16 en este trabajo. 
asir 3. prnl. Agarrarse de algo. Asirse de una cuerda. U. t. en sent. fig. Asirse a una idea.

Esta decisión de eliminar las marcas de transición semántica no solo atañe al DRAE 2001; lo mismo ocurre con el DUE de María Moliner, que ya en la edición de 1999 eliminó por completo estas abreviaturas presentes en la primera edición. En esta edición del Diccionario de uso del español de María Moliner (1966-1967) aparece entre la lista de abreviaturas que emplea el repertorio la correspondiente a la marca figurado (fig.), pero en la $2^{\mathrm{a}}$ y en la $3^{\mathrm{a}}$ edición se suprime esta marca en el listado, aunque sí se empleará en el interior del artículo lexicográfico cuando la acepción o subacepción se aparte claramente del significado original.

abducir (del lat. abducěre) tr. Secuestrar supuestamente los extraterrestres a seres humanos. 5 inf. También en sentido figurado: 'Ha sido abducido por la televisión basura'.

En los preliminares de la obra se informa de que las indicaciones que se ofrecen en el diccionario han sido objeto de una minuciosa revisión y aunque no se señala explícitamente que se ha renunciado a este tipo de información complementaria ni los motivos para hacerlo, ni siquiera aparece en la tabla de abreviaturas empleadas por el repertorio. Para obtener esta información se debe realizar a través de las 'búsquedas avanzadas' incluyendo esta información en la definición ${ }^{19}$.

En el Diccionario del español actual, de Manuel Seco, Olimpia Andrés y Gabino Ramos (1999) (DEA), se hace un uso muy restringido de las marcas de transición semántica por las características mismas del propio repertorio. Estamos ante una obra elaborada a partir de un corpus seleccionado con el fin de dar cuenta de los empleos actuales de los vocablos. El hecho de ceñirse a los usos actuales hace que carezca de sentido marcar significados como figurados, cuando no se va a dar cuenta de una hipotética evolución sobre significados anteriores usuales o no, y cuando muchas veces encabezan el artículo lexicográfico o un grupo de acepciones concreto.

Por ello, la mayoría de los ejemplos que hemos extraído del DRAE (2001), marcados como de uso figurado, no lo están en el DEA; esto sucede con agresión, cornamenta, derrumbar, deshielo, invertir, remojón, y otros muchos ejemplos. Sin embargo, no se renuncia a señalar en esta obra el hecho de que un significado tenga un empleo translaticio que no altere en lo básico el semema del término y no merezca por tanto una nueva acepción o subacepción; en ese caso, se indica esta información con la abreviatura «fig.» (figurado), pero situada detrás de la definición, como en los siguientes ejemplos:

alud Masa grande de nieve que se precipita por la ladera de una montaña. Frec fig., en este caso, normalmente con complemento especificador.

fecundar 3 Hacer que [algo o alguien (cd)] sea fértil o productivo. Tb. Fig.

${ }^{19}$ Si lo que nos interesa es extraer todas aquellas entradas que tengan un sentido figurado, habrá que escribir 'en sentido figurado' para obtener todas aquellas voces que incluyen en alguna acepción o subacepción esta valoración. 
Los propios autores de la obra dan cuenta de esta forma de indicar los usos figurados de un término en la Guía del lector, que antecede al propio diccionario: «La existencia de un uso metafórico, cuando no está lo suficientemente independizado respecto al sentido definido y no parece definitivamente cuajado en otro distinto, se advierte por medio de la nota también figurado ( $t$ b. fig.)» (1999: xxii).

lifting Operación de cirugía plástica que tiene por objeto la eliminación de las arrugas de la cara y cuello. Tb. fig. referido a cosas.

fagocitar $\operatorname{tr}$ (Biol) Ingerir por fagocitosis. Tb. fig., fuera del ámbito técnico.

Siguiendo con el último de los diccionarios revisados, el LEMA (2001) es el único diccionario que hace referencia explícita en los preliminares de la obra a los neologismos formales y semánticos, indicando que:

[...] son varios miles los significados que no se encontraban en otros diccionarios VOX. Responden estas nuevas acepciones a usos diferenciados por los sentidos, por las construcciones sintácticas en que la voz aparece, por la selección de palabras que presenta y por el tipo de discurso en que suele presentarse (2001: VIII).

También en el apartado de «Abreviaturas» recoge en el subapartado «Otras» la abreviatura de fig. 'figurado'. De igual modo en la entrada léxica cambio incluye un cuadro que resume los principales procesos de cambio semántico, muy relacionado con tipo de neologismos que estamos analizando:

Aunque pueda parecer que el significado de las palabras es estable, en el uso diario de la lengua éstas adquieren a menudo nuevos sentidos. [...] Los procesos en los que se basa la creación de nuevos sentidos son muy variados, pero no infinitos, ya que existen ciertos patrones recurrentes (2001: 298).

De estos procesos destaca la metáfora, la metonimia, la etimología popular y la elipsis. Más adelante indica que al producirse un cambio semántico el contenido semántico de una palabra «puede experimentar una ampliación, una restricción o una alteración de su significado» (2001: 299).

También se muestra en los ejemplos los usos metafóricos de la voz: el sentido de la voz entrada puede interpretarse a partir del significado definido.

amurallar v tr Proteger un lugar con murallas [...] (fig) El Real Zaragoza se amuralló para conseguir su primer punto.

abatir 1 tirar o hacer caer al suelo a una persona o cosa que está de pie o en un lugar alto, generalmente con fuerza o ímpetu (fig) La crisis del siglo XIV abatió las zonas agrícolas.

Analicemos cuantitativamente esta información complementaria que figura en las obras estudiadas y su modo de representación, pues como hemos visto, el ámbito de la transición semántica en el diccionario se nos muestra como un campo que se sigue representando. Para darnos cuenta de lo que esto supone vamos a intentar describir 
mínimamente el ámbito de la transición semántica dentro del aparato de abreviaturas o marcas utilizado por los diccionarios analizados DRAE y el DUE ${ }^{20}$.

\begin{tabular}{|l|l|l|}
\hline Marcas & DRAE & DUE \\
\hline Especialmente & 1870 & 1367 \\
\hline Por extensión & 118 & 359 \\
\hline Por analogía & 4 & 14 \\
\hline Figurado & 291 & 321 \\
\hline Por antonomasia & 90 & 50 \\
\hline
\end{tabular}

Tabla 2. Número de marcas de transición semántica

Centrándonos en el DRAE2001, la representación de cada una de ellas es la siguiente: En el caso del sentido figurado aparece en 295 acepciones como nota de uso, de las cuales 292 son actuales y 3 son antiguas (aperreador-ra; apedernalado-a; despender). De las primeras en 291 solo ofrece información sobre la transición semántica y en una incluye también información geográfica (veranito de San Juan). Las abreviaturas que incluye son las siguientes:

\begin{tabular}{|l|c|}
\hline Transición semántica: figurado & $\mathbf{N}^{\mathbf{0}}$ de apariciones \\
\hline u. en sent. fig. & 1 \\
\hline u. . en sent.fig. & 12 \\
\hline u. t. en sent. fig. & 279 \\
\hline
\end{tabular}

Tabla 3. La transición semántica en el DRAE (2001): sentido figurado

En cuanto a otras marcas valorativas que introducen cambios semánticos encontramos las siguientes:

\begin{tabular}{|l|l|c|}
\hline Transición semántica & Abreviatura & $\mathbf{N}^{\mathbf{0}}$ apariciones \\
\hline Antonomasia & por anton. & 90 \\
\hline \multirow{2}{*}{ Por extensión } & por ext. & 118 \\
\hline \multirow{2}{*}{ Por analogía } & por anal. & 3 \\
\hline \multirow{2}{*}{ Especialmente (1870) } & Se usa especialmente & 16 \\
\cline { 2 - 3 } & Se aplica especialmente & 5 \\
\cline { 2 - 3 } & Usado especialmente & 10 \\
\hline
\end{tabular}

Tabla 4. Otras marcas de transición semántica en el DRAE (2001)

${ }^{20}$ Esta información nos la ofrece la versión en CD-ROM del diccionario académico y del DUE. Al no disponer de versión digital en el caso del DEA y del LEMA, este estudio cuantitativo no se ha podido realizar. 
En el caso del DUE la representación de la información sobre la transición semántica queda del siguiente modo:

\begin{tabular}{|l|l|c|}
\hline $\begin{array}{l}\text { Expresión de transición } \\
\text { semántica }\end{array}$ & \multicolumn{1}{|c|}{ Abreviatura } & No apariciones \\
\hline \multirow{2}{*}{ En sentido figurado } & En sentido figurado & 321 \\
\cline { 2 - 3 } & Figuradamente & 41 \\
\hline Por extensión & & 359 \\
\hline Por analogía & & 14 \\
\hline Por antonomasia & & 50 \\
\hline Especialmente (1367) & Se usa especialmente & 51 \\
\cline { 2 - 3 } & Se aplica especialmente & 72 \\
\cline { 2 - 3 } & Usado especialmente & 18 \\
\hline
\end{tabular}

Tabla 5. Marcas de transición semántica en el DUE (2007)

Como conclusión a este apartado, podemos señalar que ha habido un progresivo descenso de acepciones marcadas con estas informaciones en los diccionarios del español y se observa una falta de criterio homogéneo a la hora de aplicar estas etiquetas.

\section{ANÁLISIS Y RESULTADOS}

Para la realización de este análisis hemos dividido el estudio en dos partes. En la primera se analizará el primer tipo de neologismos semánticos señalado anteriormente a partir de la creación de un nuevo significado para una palabra ya existente y su representación en los diccionarios del español. En la segunda nos centraremos en el otro tipo de neologismos semántico caracterizado a partir de un nombre propio o de marca.

\subsection{Representación de los nuevos significados en palabras ya documentadas}

Los neologismos semánticos conllevan la creación de un nuevo significado de una palabra ya existente, y por eso, cuando los diccionarios añaden un nuevo significado, a veces indican a través de una marca valorativa la relación que el significado nuevo mantiene con el inicial. Como los diccionarios no incluyen explicaciones sobre el tratamiento de los significados nuevos en los artículos lexicográficos, a la hora de analizarlos debemos fijarnos en las marcas valorativas como 'especialmente', 'por extensión', 'por analogía' y 'figurado', que sirven para indicar ampliaciones o restricciones de significado o cambios del significado de una unidad producidos por procesos metafóricos o metonímicos.

A partir de este punto y partiendo del estudio realizado por Judit Freixa y Elisabet Solé (2004) en el capítulo 7 dedicado a la neología semántica en su libro Llengua catalana $i$ neología, hemos buscado aquellas marcas que introducen un nuevo significado en diversos diccionarios del español.

Por lo que respecta a los diccionarios analizados, a través del análisis de las principales marcas valorativas de uso que utilizan para indicar relaciones semánticas entre los diferen- 
tes significados de una entrada, veremos cómo se reflejan estos cambios semánticos mediante la ampliación del significado (marca por extensión), restricciones de significado (marca especialmente), cambios de significado por analogía (marca por analogía) o por metáfora o metonimia (mediante la marca figurado).

Tras la revisión de las obras lexicográficas empleadas como referencia se observa que se sigue aplicando este tipo de marcación, pero el examen revela también que no existe un procedimiento sistemático dentro de una misma obra o respecto a una misma unidad, si comparamos obras lexicográficas distintas. Es necesario, por tanto, señalar que no hay una delimitación clara de los usos de cada marca, lo que se refleja en un empleo asistemático de las etiquetas de transición semántica. Esta asistematicidad se da en la marcación de casos idénticos que corresponden a una misma marca y que aparecen tanto con etiqueta como sin ella, o con etiquetas diferentes, lo cual muestra que los desplazamientos semánticos quedan supeditados al criterio del autor o autores de la obra.

agape

ágape $1 . \mathrm{m}$. Comida fraternal de carácter religioso entre los primeros cristianos, destinada a estrechar los lazos que los unían.2. m. banquete (\| comida para celebrar algún acontecimiento). [DRAE]

ágape $\mathbf{m}$. Entre los primeros cristianos, *banquete o * convite de caridad. 5 (a veces con sentido irónicamente culto) Por extensión comida con que se celebra algo: 'Hay que festejar esto con un ágape'. [DUE]

ágape 1. (lit) Banquete o comida con motivo de una celebración. Frec con intención humorística. 2. (hist) Comida comunitaria de los primeros cristianos. [DEA]

ágape 1. Comida a la que asisten muchas personas y en la que se celebra un acontecimiento 2. Comida fraternal de carácter religioso que se celebraba entre los cristianos. [LEMA]

\section{fichar}

fichar 5. tr. Contratar a un deportista para que forme parte de un equipo o club, y, por ext., a una persona para que desarrolle otra profesión o actividad. [DRAE]

fichar 4 Contratar un equipo u organización deportiva, particularmente de fútbol, a un jugador. 5 Por extensión, contratar a alguien, generalmente de alto nivel, para un puesto o cargo.

5 intr. Dep. (por) Contratarse un jugador para jugar en determinado equipo: 'Ha fichado por el Real Madrid'. 5 Por extensión, contratarse otras personas para trabajar en un puesto o cargo. [DUE]

fichar 3. Dep. Contratar (a un jugador o a un técnico). Tb. Fig. fuera del ámbito deportivo. [DEA]

fichar 3. Contratar una organización empresarial o deportiva a alguien. [LEMA]

Por otra parte, se hace un uso abusivo de las marcas que a menudo son innecesarias.

sublime (Del lat. sublīmis).1. adj. Excelso, eminente, de elevación extraordinaria. U. m. en sent. fig. apl. a cosas morales o intelectuales. Se dice especialmente de las concepciones mentales y de las producciones literarias y artísticas o de lo que en 
ellas tiene por caracteres distintivos grandeza y sencillez admirables. Se aplica también a las personas. Orador, escritor, pintor sublime. [DRAE]

Pasemos al análisis de cada una de estas marcas de transición semántica.

\section{1) Especialmente}

Después de analizar una serie de entradas, podemos indicar que la mayoría de las acepciones marcadas con la expresión especialmente o algunas de sus variantes (se usa especialmente, se aplica especialmente, usado especialmente, etc.) indican una restricción de significado respecto de la acepción de referencia. Estas restricciones se reflejan en el estilo definitorio de las diferentes acepciones de diversas maneras:

Generalmente se mantiene el descriptor y se añaden informaciones específicas que restringen el uso o el ámbito de aplicación. Mientras que en el DRAE se incluye dentro de la misma acepción, en el DUE se marca como subacepción de la acepción primera.

acartonarse.1. prnl. Ponerse como cartón. Se usa especialmente hablando de las personas que al llegar a cierta edad se quedan enjutas. [DRAE]

sobresaltar3. intr. Dicho de una cosa: Venirse a los ojos. Se usa especialmente hablando de las pinturas cuando las figuras parece que salen del lienzo. [DRAE]

superdotado, da.1. adj. Dicho de una persona: Que posee cualidades que exceden de lo normal. Se usa especialmente refiriéndose a las condiciones intelectuales. [DRAE]

aliñar 1 tr. Añadir a las comidas el arreglo necesario de condimentos para que estén gustosas. *Condimentar. $\Theta$ Se emplea especialmente para la acción de poner a las ensaladas el aceite, el vinagre y la sal. 2 Adeliñar, deliñar. [DUE]

aprovisionar tr. (con, de) Proporcionar a alguien lo que necesita de comida, vestidos, etc. $\Theta$ Se aplica especialmente a barcos y unidades militares. También reflex. $1 *$ Abastecer, *proveer. [DUE]

En otros casos, el descriptor de la segunda acepción recoge toda la definición precedente y añade alguna especificación.

macrófago, -a adj. Biol. Se aplica a las células capaces de fagocitar cuerpos extraños voluminosos. $\Theta$ adj. y n. m. Biol. Se aplica especialmente a los glóbulos blancos. [DUE]

Hay un cambio en las restricciones semánticas que subcategoriza la primera acepción, que pasan a ser más restringidas en la segunda acepción

multimedia (pl. multimedia) 1 adj. Que se basa en la utilización de varios medios de comunicación: 'Una campaña publicitaria multimedia. Un método multimedia de aprendizaje del inglés'. $\mathbf{2}$ adj. y n. m. Se aplica especialmente al sistema informático que utiliza imágenes, texto y sonido: 'Un ordenador multimedia'. [DUE]

La subacepción de significado es más restrictiva y suele pertenecer a un área temática concreta, produciéndose el fenómeno de la terminologización.

alabardado, -a adj. En *forma de alabarda: 'Puñal alabardado'. $\Theta$ Se usa especialmente en botánica: 'Sépalo alabardado'. [DUE]

basilar adj. De la base. $\Theta$ Se usa especialmente en anatomía. [DUE] 
competencial adj. De las competencias de determinada persona, entidad, etc. $\Theta S e$ emplea especialmente en política: 'Ámbito [marco o techo] competencial. Conflictos competenciales'. [DUE]

productividad f. Cualidad de productivo. $\Theta$ Se emplea especialmente en el campo de la industria: 'Aumentar la productividad'. [DUE]

\section{2) Por extensión}

Con esta etiqueta se indica que hay una ampliación del significado precedente, de manera que la segunda acepción tiene una definición de carácter más general que la primera.

Según indica el DUE por extensión 'Se aplica al empleo de las palabras o expresiones con un significado que no es el suyo propio, pero tiene con él una relación objetiva'.

Si nos fijamos en algunas de las entradas introducidas con esta valoración, encontramos:

a) Hay una ampliación semántica de los elementos con respecto a la primera acepción.

\section{[DUE]}

ábaco (del lat. abăcus, del gr. ábax)

$1 \mathbf{m}$. Marco de madera que sostiene diez cables, en cada uno de los cuales hay pasadas diez bolas, que se empleaba en las escuelas para enseñar a * contar. 1 Tablero contador.

2 Por extensión, cualquier tabla o cuadro que se empleaba para efectuar algún cómputo o cálculo.

agalla (de $a-{ }^{2}$ y el lat. galla) 1 f. Bot. Cecidio globuloso que suele formarse en los *robles y otras especies del género Quercus. Las del roble (llamadas también cacarro, cecidia, gállara, gargal, tora, zonzorro) tienen abundante tanino, por lo que se emplean para curtir, en tintorería y también en medicina. $\Theta$ Bot. Por extensión, cecidio en cualquier planta.

estupro (del lat. stuprum) $\mathbf{m}$. Der. *Delito que consiste en realizar el coito con una persona menor de edad, aprovechándose de una situación de superioridad o con engaño. $\Theta$ Der. Por extensión, violación

llevar al huerto inf. Conseguir una persona que otra acceda a mantener relaciones sexuales con ella. $\Theta$ inf. Por extensión, conseguir alguien que otro acceda a sus pretensiones.

aceite (del ár. and. azzáyt, cl. azzayt, de or. arameo) 1 m. *Grasa extraída de algún vegetal. 5 Específicamente, la que se emplea para guisar. 2 Por extensión, cualquier otra *grasa líquida, particularmente las que se emplean como lubrificantes o combustibles.

cortarse la coleta Retirarse los toreros del toreo. $\Theta$ Por extensión, abandonar una profesión o una actividad cualquiera

\section{[DRAE]}

comicios (Del lat. comitǐum).1. m. pl. Elecciones para designar cargos políticos.2. m. pl. Junta que tenían los romanos para tratar de los negocios públicos, $\mathrm{y}$, por ext., otras reuniones.

fletar.(De flete).1. tr. Dar o tomar a flete un buque y, por ext., otro vehículo terres$\underline{\text { tre o aéreo }}$ 
misa de campaña 1 . f. La que se celebra al aire libre para fuerzas armadas $\mathrm{y}$, por ext., para un gran concurso de gente

piñata $2 \mathrm{f}$. Vasija de barro, llena de dulces, que en el baile de máscaras del primer domingo de Cuaresma suele colgarse del techo para que algunos de los concurrentes, con los ojos vendados, procuren romperla de un palo o bastonazo, y, por ext., la que se pone en una fiesta familiar, de cumpleaños o infantil.

tata.(Del lat. tata).1. f. coloq. Niñera y, por ext., muchacha de servicio.

En ocasiones, el descriptor de la segunda acepción es un hiperónimo del descriptor de la primera.

\section{[DUE]}

ágape (del lat. agăpe, del gr. agápē, amor)

m. Entre los primeros cristianos, *banquete o * convite de caridad. $\Theta$ (a veces con sentido irónicamente culto) Por extensión comida con que se celebra algo: 'Hay que festejar esto con un ágape'.

baba $^{1}$ (del sup. lat. baba)

1 f. (sing. o pl.) * Saliva que escurre de la boca. $\Theta$ Por extensión, cualquier secreción viscosa de animales o plantas y de otras cosas no orgánicas. Particularmente, la del caracol

\section{[DRAE]}

a bordo 1. loc. adv. En una embarcación y, por ext., en otros vehículos. Comer a bordo.

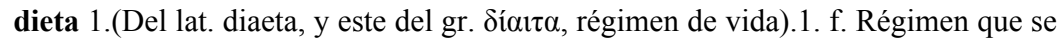
manda observar a los enfermos o convalecientes en el comer y beber, y, por ext., esta comida y bebida.

b) En algunos casos esta marca también se utiliza para indicar una relación de metonimia de la segunda acepción respecto de la primera.

\section{[DUE]}

contrafuerte 3 Pieza de cuero con que se refuerza interiormente la parte de detrás del * calzado. $\Theta$ Por extensión, esa parte del calzado o la costura que hay en ella: 'Me ha hecho una herida el contrafuerte del zapato'. [la parte por el todo]

dorsal $4 \mathbf{m}$. Trozo de tela con un número que llevan en la espalda los participantes de una competición. $\Theta$ Por extensión, participante que lleva un dorsal: 'Ha ganado la carrera el dorsal número 7'. [El agente por el objeto o instrumento]

escaño 1 m. *Banco con respaldo. $\Theta$ Asiento de cada diputado en el *congreso. $\Theta$ Por extensión, puesto de parlamentario. [el objeto por la persona responsable]

bafle $\mathbf{m}$. Plancha sobre la que se monta un altavoz para mejorar la calidad del sonido. $\Theta$ Por extensión, designa el altavoz y todo el dispositivo en que está contenido.[el continente por el contenido]

Se aplica (también) es una marca que se emplea en 304 ocasiones en el DUE. En muchos casos se emplea para indicar una ampliación de significado como por ejemplo en las entradas como en los siguientes ejemplos

birria 2 (n. calif.) Se aplica a una cosa mal hecha, de mal aspecto, sin mérito o fea: 'Ese traje es una birria. Ha escrito una novela que es una birria'. $\Theta$ Se aplica también a personas: 'Su novio es una birria'. 2 *Chapuza, *desastre, fracaso. 
monigote 2 Persona *insignificante o despreciable. $\Theta$ Persona de poco *carácter, que se deja *manejar por otros. $\Theta$ Se aplica como insulto cariñoso a los *niños.

petardo $8 \mathrm{f}$. inf. Mujer frívola, amante del pertadeo. $\Theta$ inf. Se aplica también a hombres amanerados, especialmente homosexuales.

\section{3) Por analogía}

Se ha relacionado esta etiqueta con el cambio de significado que se produce por semejanza $^{21}$ :

a) Casos en que el mismo significado se aplica a cosas diferentes por semejanza: se mantiene el descriptor, pero las restricciones semánticas son diferentes (ni más amplias ni más restrictivas).

\section{[DRAE]}

delantal (De delante) $1 \mathrm{~m}$. Prenda de vestir que, atada a la cintura, usan las mujeres para cubrir la delantera de la falda, y por analogía, el que usan algunos artesanos, los criados, los camareros y los niños.

b) Casos en los que hay un cambio claro de significado, el cual se produce por una similitud en la forma, la finalidad o el tipo de acción.

b1) Por la forma:

\section{[DUE]}

estilográfico, -a 1 adj. y n. f. Se aplica a la *pluma que escribe con tinta contenida en un depósito que lleva ella misma. $\mathbf{2}$ adj. y n. m. Por analogía, se aplica al lápiz provisto de una mina recambiable que puede hacerse asomar por la punta o retirarse al interior.

escama $^{1} 1$ f. Cada una de las *láminas o placas, yuxtapuestas o imbricadas, que revisten el cuerpo de diversos animales, por ejemplo el de los peces. [...] 2 Por analogía, cada una de las piezas que forman la loriga. $\mathbf{3}$ Se aplica también a cosas de *forma más o menos parecida a las escamas; por ejemplo, a las laminillas que se desprenden de la piel y de otros sitios o a las que se forman con algunos productos: 'Escamas de jabón'.

\section{[DRAE]}

botón de mando.1. $\mathrm{m}$. Tecla de un aparato, por analogía con el botón del timbre.

b2) Por la finalidad

\section{[DUE]}

foro $1 \mathrm{~m}$. En la *Roma antigua plaza donde se celebraban las *reuniones públicas y donde el pretor celebraba los juicios, como la que todavía se conserva en ruinas en la ciudad de Roma. 2 Por analogía, lugar donde actúan los *tribunales que administran justicia. 2 Forense. 3 Por extensión, ejercicio de la abogacía: 'Dedicarse al foro'.

${ }^{21}$ Se emplea esta marca para indicar también analogía o semejanza en la forma gráfica en las siguientes entradas del DUE: barlovento (de barloa y la terminación -vento, por analogía con sotavento); nucleótido (de núcleo e -ido ${ }^{l}$, con una $t$ por analogía con -tico, siguiendo el modelo del al. Nucleotid); rayón $^{3}$ (del ingl. rayon, de ray, rayo de luz, y -on, por analogía con otros nombres de tejidos, como cotton, algodón). 
odeón m. *Teatro donde se daban en Grecia espectáculos musicales. Por analogía, se aplica algunas veces como nombre propio a un teatro especialmente destinado a ópera o espectáculos musicales.

b3) Por el tipo de acción

\section{[DUE]}

rugir 1 intr. Emitir su sonido vocal propio el león, el tigre u otras fieras que lo tienen semejante. 2 *Voz. 2 Por analogía, producir un ruido fuerte y ronco algunas cosas como el mar o la tempestad. 1 *Bramar.

\section{4) Figurado}

En la mayoría de los casos solo se indica que una acepción o subacepción tiene un sentido figurado. Si buscamos figurado en el DRAE, nos dice:

2. adj. Se dice del sentido en que se toman las palabras para que denoten idea diversa de la que recta y literalmente significan.

Esto es, el sentido figurado indica que el significado se desvía de lo que se considera el significado recto o primario.

Por lo que respecta al uso que hacen los diccionarios, la mayoría de los significados que se encuentran marcados como figurado son fruto de una metáfora producida a partir de la acepción de referencia. Según el grado de fijación de esta metáfora en la lengua podemos establecer dos grandes grupos de casos.

a) En cuanto a la formulación de la definición figurada de la segunda acepción o subacepción el referente de la primera acepción es muy cercano.

En el caso del diccionario académico se limita a añadir al final de la acepción una etiqueta U. t. en sent. fig. o U. m. en sent. fig.

gracia.1. f. Cualidad o conjunto de cualidades que hacen agradable a la persona o cosa que las tiene. U. t. en sent. fig.

mordaza1. f. Instrumento que se pone en la boca para impedir el hablar. U. t. en sent. fig.

taponar 2. tr. Obstruir o atascar un conducto o paso. U. t. en sent. fig.

\section{Lo mismo ocurre en el DUE}

parálisis f. Med. Pérdida de la capacidad de *movimiento de alguna parte del cuerpo: 'Un ataque de parálisis'. Se usa también en sentido figurado.

edulcorar tr. o abs. Endulzar con sustancias naturales o sintéticas. $\Theta$ Se usa con frecuencia figuradamente.

maniatar 1 tr. Atar las manos a alguien. 2 *Apear. 2 Se usa con frecuencia figuradamente.

En algunos casos se incluye un ejemplo que aclara el uso figurado de la acepción. En el caso del DRAE de las 295 acepciones marcadas como figuradas, solo en 17 se incluye un ejemplo.

abismo 1. m. Profundidad grande, imponente y peligrosa, como la de los mares, la de un tajo, la de una sima, etc. U. t. en sent. fig. Se sumió en el abismo de la desesperación. 
apoderar prnl. Hacerse dueño de algo, ocuparlo, ponerlo bajo su poder. U. t. en sent. fig. El pánico se apoderó de los espectadores.

lifting.(Voz ingl.).1. m. Operación de cirugía estética consistente en el estiramiento de la piel, generalmente de cara y cuello, para suprimir las arrugas. U. t. en sent. fig. Los teatros de la ciudad necesitan un lifting

penetrar Introducirse en un lugar. U. m. c. intr. U. t. en sent. fig. Las ideas ilustradas penetraron el país con rapidez.

En el DUE esta información es mucho más frecuente, ya que la mayoría de las subacepciones figuradas incluyen un ejemplo que ilustra este uso.

saltar por los aires Hacer que alguien o algo salten por el aire destrozados a causa de una explosición. 2 *Destruir. $\Theta$ También en sentido figurado: 'El acuerdo saltó por los aires'.

vía muerta 1 En las * estaciones de ferrocarril, la que no tiene salida y sirve para apartar de la circulación vagones o máquinas. 2 *Separar. 2 Puede usarse en sentido figurado: 'Las investigaciones están en vía muerta'.

refrescante adj. Se aplica a lo que refresca. $\Theta$ Apto para refrescar. $\Theta$ Se aplica a lo que produce una sensación agradable de frescor: 'Una brisa refrescante'. $\Theta \mathrm{Se}$ usa también en sentido figurado: 'Un artículo refrescante'.

terremoto m. Sacudida producida en algún punto de la Tierra, por fenómenos internos. 5 También en sentido figurado: 'Sus declaraciones han provocado un auténtico terremoto político'.

síndrome $1 \mathrm{~m}$. Med. Conjunto de *síntomas de una afección. 2 Se usa también en sentido figurado: 'Tiene el síndrome del parado'.

termómetro m. Aparato que sirve para medir la temperatura, basado en la dilatación de un cuerpo; generalmente, del mercurio encerrado en un tubo capilar. $\Theta \mathrm{Se}$ usa también figuradamente: 'Termómetro político'.

b) En otras ocasiones el uso figurado se emplea cuando se aplica a un determinado ámbito, objeto, etc.

\section{[DRAE]}

anteojera.1. f. Caja en que se tienen o guardan anteojos.2. f. pl. En las guarniciones de las caballerías de tiro, piezas de vaqueta que caen junto a los ojos del animal, para que no vean por los lados, sino de frente. Apl. a pers., u. t. en sent. fig.

codo a codo loc. adv. Dicho de personas: Unas juntas a otras en compañía o cooperación. Apl. a cosas, u. t. en sent. fig.

desastre 2. $\mathrm{m}$. Cosa de mala calidad, mal resultado, mala organización, mal aspecto, etc. Un desastre de oficina. Apl. a pers., u. t. en sent. fig.

sublime 1. adj. Excelso, eminente, de elevación extraordinaria. U. m. en sent. fig. apl. a cosas morales o intelectuales. Se dice especialmente de las concepciones mentales y de las producciones literarias y artísticas o de lo que en ellas tiene por caracteres distintivos grandeza y sencillez admirables. Se aplica también a las personas. Orador, escritor, pintor sublime.

templado, da 1. adj. Dicho de algunos materiales, como el cristal: Resistentes y sin transparencia ni brillo. Apl. a los nervios, u. t. en sent. fig.

[DUE]

aclimatar tr. *Acostumbrar a un ser orgánico a un clima o ambiente que no son aquellos en los que se ha criado. $\Theta$ prnl. *Acostumbrarse gradualmente a una si- 
tuación o un ambiente extraños o que en un principio resultan desagradables: 'Es cuestión de aclimatarse'. $\Theta$ tr. y prnl. En sentido figurado se aplica a cosas no orgánicas: 'Aclimatar una moda, una costumbre'. 2 *Establecer, *introducir.

adulto, -a adj. y n. Se aplica a la persona o animal que ha llegado a su pleno desarrollo o edad en que es apto para la procreación. $\Theta$ adj. Se aplica también, en sentido figurado, a cosas no orgánicas: 'Una lengua [o una nación] adulta'. 2 Hecho. 4 Adultez, hombre, mujer, edad adulta, mayor de edad. 4 Acmé, climaterio, desarrollo, pubertad; edad crítica.

anegar 2 Cubrir de *agua un sitio. 1 *Inundar. 5 prnl. Quedar cubierto por el agua. $\Theta$ tr. En sentido figurado se dice también de otras cosas: 'Anegar en sangre'. 2 Aniego.

sarampión m. *Enfermedad propia especialmente de la infancia, que se manifiesta al principio con síntomas catarrales que van seguidos de una *erupción de multitud de pequeñas manchas rojas sobre la piel. 2 Colorín. Alfombrilla. $\Theta$ Se usa también en sentido figurado referido a una actividad, emoción, etc., que provoca gran excitación o ansiedad pasajeras.

c) Cuando son significados diferentes que están muy fijados en la lengua: la relación de sentido figurado se establece por una similitud o analogía metafórica a partir de la forma o el aspecto físico, las cualidades humanas, la finalidad, o el tipo de acción.

\section{[DUE]}

alud $1 \mathrm{~m}$. Gran masa de *nieve, piedras, etc., que se derrumba por la ladera de una montaña. 1 Avalancha. 2 Argayo, galga, huaico, lurte, rodado. 2 Se emplea en sentido figurado o como término de comparación aplicado a algo que se precipita sobre otra cosa o sobre alguien con mucho peso o violencia: 'El ejército avanzaba como un alud'. $2 *$ Afluencia. [forma]

soltar las amarras Además de en su sentido propio, de realizar esa operación al *zarpar una embarcación, se emplea en sentido figurado con el significado de desligarse alguien de cierta dependencia o apoyo.[similitud en la acción]

vista de lince 1 Vista muy aguda o penetrante. 2 Se usa en sentido figurado con el significado de «sagacidad». [cualidad humana]

sutil 1 adj. Muy *fino: 'Un filamento sutilísimo. Unas rebanadas sutiles de membrillo. Una sutil gasa'. $\Theta$ Casi sin materia. 2 Se usa en sentido figurado envolviendo la idea de poca intensidad y gran penetración: 'Un sabor [un aroma, una diferencia, un viento] sutil'. [cualidad física]

quitarse el sombrero Hacer este gesto ante alguien como saludo o muestra de cortesía. $\Theta$ Se usa también en sentido figurado, significando demostrar o tener mucha *admiración o *respeto por algo o alguien. [tipo de acción]

recoveco $1 \mathrm{~m}$. *Torcedura o *vuelta en el curso de algo como una calle o un pasillo. 1 Revuelta. 2 Sitio escondido que resulta de la forma o disposición irregular de una cosa: 'Una casa con muchos recovecos'. 1 *Escondrijo, rincón. $\Theta$ Se usa también en sentido figurado con referencia a la manera poco clara de hablar o de ser de alguien: 'Ese chico tiene muchos recovecos'. 2 *Reservado, *retorcido. [forma]

dar la alternativa Además del significado propio anterior tiene figuradamente el de expresar con palabras o con un acto que ya se considera a alguien *apto para cierta cosa.[finalidad]

dolor de cabeza (gralm. pl.) Además de en su sentido propio, se emplea figuradamente como «preocupación». [cualidad humana] 
navajeo $1 \mathrm{~m}$. Acción de dar navajazos. 2 Se usa figuradamente para aludir al enfrentamiento verbal o mediante maniobras.[tipo de acción]

ventanilla f. 1 Ventana. $5 \mathrm{Y}$, especialmente, a las utilizadas para comunicar con el público en las *oficinas, despachos de billetes, etc. $\Theta$ Suele usarse figuradamente como representación de una *oficina o departamento oficial de atención al público: 'Se ha abierto una ventanilla única que va a permitir agilizar mucho los trámites'. [forma y finalidad]

\subsection{Representación de los nombres propios y de marcas utilizados como nombres comunes}

En los diccionarios encontramos poca información sobre este tipo de nombres. Encontramos algunos antropónimos recogidos baja una locución o subentrada.

sello de Salomón 1. m. Estrella de seis puntas formada por dos triángulos equiláteros cruzados y a la cual atribuían ciertas virtudes los cabalistas. [DRAE]

en un decir [amén] Jesús inf. En un momento; muy deprisa: 'Se cambió de traje en un decir Jesús'. 2 *Rápido. [DUE]

En el DUE aparecen además de este tipo de expresiones algunos nombres propios como entrada y etiquetados como nombres propios (14), aunque una búsqueda como 'nombre propio' en la definición aparecen muchos más: Carmen, Carracuca, Chelo, Chus, Dolores, Dulcinea, Francia, Japón, Jesús, Juan, etc.

En relación con la presencia de nombres propios se incluye la etiqueta 'por antonomasia' que consiste en el empleo de un nombre común aplicado a un nombre particular, porque es con el que con más frecuencia se aplica o el empleo de un nombre propio como genérico.

todopoderoso, -a adj. Se dice del que o lo que lo puede todo: 'Las todopoderosas influencias'. $\Theta$ (con mayúsc.) adj. y n. m. Se aplica por antonomasia a *Dios.

En cuanto a las marcas comerciales, que cuando pasan a ser nombres comunes, se convierten en un genérico del nombre propio de partida, en los preliminares del DRAE2001 se indica que:

Las marcas registradas cuyo empleo como sustantivos comunes así lo recomienda se recogen en el Diccionario haciendo constar su condición de tales, de acuerdo con la legislación vigente, en el paréntesis etimológico.

En la obra académica figuran 76 lemas con esta información:

aspirina.(Del al. Aspirin, marca reg.).1. f. Med. Sólido blanco, cristalino, constituido por ácido acetilsalićlico, que se usa como analgésico y antipirético.2. f. Comprimido fabricado con esta sustancia.

potito. (Marca reg.).1. m. Alimento envasado y preparado a modo de puré, para niños de corta edad.

Támpax. (Marca reg.).1. m. tampón (\| rollo de celulosa).

El DUE incluye denominaciones comerciales utilizadas genéricamente, como sonetone, ping-pong, pladur, etc., con la advertencia de que son marcas registradas. En concreto introduce 130 marcas registradas. 


\section{LOS NEOLOGISMOS SEMÁNTICOS EN ESPAÑOL: ANÁLISIS Y DESCRIPCIÓN EN LA PRENSA ACTUAL}

Como ya hemos comentado, dentro de la neología semántica se incluyen dos tipos diferentes de neologismos: los formados por la creación de un nuevo significado a partir de una palabra ya documentada en los repertorios lexicográficos y los nombres propios que pasan a nombres comunes.

Para llevar a cabo esta parte del estudio vamos a utilizar el banco de datos de neologismos BOBNEO $^{22}$. Es desde esta plataforma desde donde hemos reunido todos aquellos neologismos calificados como neologismos semánticos, de prensa escrita en castellano, delimitando el área geográfica a las distintas provincias que se incluyen en España (Alicante, Barcelona, Cádiz, Islas Baleares, Madrid, Málaga, Murcia, País Vasco y Navarra, Salamanca y Valencia) ${ }^{23}$ y estableciendo también un límite cronológico: desde el 01/01/2012 hasta el 30/03/2013.

A partir de las condiciones de búsqueda que hemos determinado, hemos obtenido 841 neologismos semánticos en total de los que $382^{24}$ pertenecen al español peninsular ( $\left.45^{\prime} 42 \%\right)$. Como se observa en la Tabla 1, el número de neologismos semánticos frente a otros procedimientos de creación neológica formal (8477-63'25\%) o los préstamos (3827-28'55\%) es escasamente representativo.

\begin{tabular}{|c|c|c|c|c|}
\hline $\begin{array}{c}\mathrm{N}^{\mathrm{o}} \text { TOTAL DE } \\
\text { NEOLOGIS- } \\
\text { MOS }\end{array}$ & $\begin{array}{l}\mathrm{N}^{\circ} \text { TOTAL DE } \\
\text { NEOLOGIS- } \\
\text { MOS FORMA- } \\
\text { LES }\end{array}$ & $\begin{array}{c}\mathrm{N}^{\mathrm{o}} \text { TOTAL DE } \\
\text { NEOLOGIS- } \\
\text { MOS POR } \\
\text { PRÉSTAMO }\end{array}$ & $\begin{array}{l}\mathrm{N}^{0} \text { TOTAL DE } \\
\text { NEOLOGIS- } \\
\text { MOS SEMÁN- } \\
\text { TICOS }\end{array}$ & $\begin{array}{l}\text { NEOLOGIS- } \\
\text { MOS SE- } \\
\text { MÁNTICOS } \\
\text { EN ESPAÑA }\end{array}$ \\
\hline 13400 & 8477 & 3827 & 841 & 382 \\
\hline
\end{tabular}

Tabla 6. Número de neologismos en BOBNEO

Aunque sin entrar en profundidad en el análisis de los mecanismos empleados para la creación de nuevos significados a partir de significantes ya existentes, nos parece oportuno acabar este estudio con una muestra de los neologismos semánticos creados en el último año y los procedimientos que se han empleado para ello.

${ }^{22}$ El Institut Universitari de Linguistica Aplicada (IULA) de la Universidad Pompeu Fabra de Barcelona ha puesto a disposición de todo el mundo toda una serie de recursos fruto de los trabajos que viene realizando su Observatorio de Neologia (OBNEO). Así, por ejemplo, en la página web del IULA es posible disponer en línea de una herramienta de consulta de su base de datos de neologismos, que ofrece los neologismos léxicos procedentes de los medios de comunicación, escritos y orales, en catalán y en español, recogidos desde 1992. La herramienta ofrece una gran variedad de combinaciones para la selección de las posibles búsquedas: por fecha, región, fuente y, por supuesto, tipo de neologismo

${ }^{23}$ Hemos dejado fuera los neologismos semánticos producidos en el Español de América por razones de tiempo y espacio, pero sería interesante para un futuro trabajo estudiar las diferencias de productividad neológica desde el punto de vista semántico entre el español peninsular y el hispanoamericano.

${ }^{24}$ Los resultados obtenidos en la búsqueda realizada suman los ítems repetidos en todos los casos, ya que nos interesaba obtener todos los contextos de uso. No obstante, se puede realizar la búsqueda excluyendo los neologismos repetidos. 
Así el mecanismo de formación de palabras con un significado nuevo a partir de un nombre propio que se convierte en nombre común es un recurso bastante relevante en el campo de la neología. Del total de 382 neologismos semánticos hallados en el último año, un $9^{\prime} 68 \%$ de unidades utiliza este procedimiento.

Para analizar los nombres propios que pasan a nombres comunes tenemos que tener en cuenta el origen del nombre propio y para ello partimos de la clasificación establecida en Feliu et al (2009: 95), lo que quedaría del siguiente modo:

a) Marcas comerciales (22): barbie, bicing, botox, caterpillar, cleenex, cocacola, instagram, iPad, iPhone, mobilette, monopoly, pantone, pemetrexed, photoshop, playstation, post-it, power point, tetra pak, túrmix, twitter, vespino.

b) Personajes ficticios (4): pantagruel, pitufo, superman, terminator.

c) Antropónimos (8): beatle, bikram, choni, españolista, lolaila, pilates, polisario, theremin.

d) Topónimos (1): arborio

Como podemos ver según los datos obtenidos la mayoría de los nombres propios que han pasado a nombres comunes son marcas registradas (59'45\%), y ninguno de ellos está presente en los diccionarios analizados, excepto vespino que figura en el DRAE como avance de la tercera edición.

El resto de neologismos semánticos hallados en la consulta realizada a OBNEO, $345-90 ' 31 \%$, corresponden a significados nuevos a partir de acepciones ya recogidas en el DRAE o en el LEMA, diccionarios de referencia. Excepto algunos casos basados en procesos metonímicos como boina roja, o unidades que designan entidades deportivas (bermellón, roja), la mayoría de las voces encontradas se basan en un proceso de ampliación de significado a partir del significado documentado en los repertorios lexicográficos de referencia ${ }^{25}$.

Si analizamos las creaciones léxicas obtenidas en nuestra búsqueda se observa que la mayoría de los ejemplos son producidos por el fenómeno de la polisemia, generalmente por una extensión del significado. Hemos recogido en este grupo todos aquellos neologismos que aportaban un significado nuevo a una palabra ya existente en los diccionarios, y mantienen con ese significado una relación de analogía o de semejanza. La metáfora y la metonimia son las figuras retóricas más utilizadas en la creación de estos neologismos. Sirva como muestra algunos ejemplos ${ }^{26}$ :

\section{anestesiar}

[DRAE] 1. tr. Privar total o parcialmente de la sensibilidad por medio de la anestesia.

[Analogía por la acción/resultado]En lo que sí se ponían de acuerdo era en considerar que Berlusconi posee un talento empresarial y propagandístico extraordinario, y que ya no cabe menospreciarlo ni como adversario ni como amenaza real y

${ }^{25}$ Dejamos fuera los llamados neologismos pseudosemánticos llamados así porque utilizan dos procesos de formación. Por un lado, son neologismos semánticos porque formalmente coinciden con una palabra ya existente, pero por otra, emplea otros procesos de carácter formal como la abreviación o el calco (Freixa 2004: 204).

${ }^{26}$ Dejamos este análisis para un próximo estudio que se centrará en los procesos cognitivos que motivan la creación de un neologismo semántico. 
seria. En que, a través de sus televisiones y periódicos, de sus sobornos y escándalos, ha conseguido *anestesiar* a buena parte de la población.

\section{Auditoría}

[DRAE] auditoría contable 1. f. Revisión de la contabilidad de una empresa, de una sociedad, etc., realizada por un auditor.

[Analogía por la finalidad] Después de todo, si hay empresas que le encargan una *auditoría* moral, ¿por qué no puedo creer que podemos contribuir a la creación de un mundo más ético?

bucle

[DRAE] bucle.1. $\mathrm{m}$. Rizo de cabello en forma helicoidal.

[Analogía por la forma] En un entorno de menor crecimiento del mercado, y afectados por la desagregación de *bucles*, los accesos de telefonía fija minorista se sitúan en 12,7 millones en junio de 2011. [Acción Telefónica, 01/09/2012]

\section{condimentar}

[DRAE] condimentar (De condimento). 1. tr. sazonar (\| la comida).

[metáfora] Esta edición entre España y Argentina está *condimentada* por el sabor de la revancha. [Tenis World, 12/01/2012]

\section{gasolina}

[DRAE] gasolina. (Del ingl. gasoline, de gas, -ol y -ene). 1. f. Mezcla de hidrocarburos líquidos volátiles e inflamables obtenidos del petróleo crudo, que se usa como combustible en diversos tipos de motores.

[metáfora] La *gasolina* tiene límites: como Atlas tiene que soportar el peso sobre sus hombros de la bóveda celeste, los tenistas deben cargar sobre sus piernas la dureza a la que somete el calendario. [Tenis World, 12/01/2012]

\section{pantalla}

$[\text { DNEOL }]^{27}$ pantalla electrónica f. Superficie en la que aparecen imágenes en ciertos aparatos electrónicos.

[metonimia] ¿Puede afirmarse, como sostienen estos críticos, que los institutos pierden el tren de la modernidad por no organizar sus clases en torno al ordenador? De momento, la *pantalla* ha generado más costes que beneficios. [LV, $16 / 12 / 2011]$.

\section{pilotar}

[DRAE] pilotar. 1. tr. Dirigir un buque, especialmente a la entrada o salida de puertos, barras, etc. 2. tr. Dirigir un automóvil, globo, aeroplano, etc.

[analogía por la acción] El dirigente yemení, que tras 32 años en el poder se ha declarado dispuesto a adelantar las elecciones a primeros de 2012, se empeña sin embargo en *pilotar* el periodo transitorio hasta entonces. [EP, 09/04/2011, INTER, $3,22 / 09 / 2011]$

\section{tijeretazo}

[DRAE] tijeretazo (De tijereta). 1. m. Corte hecho de un golpe con las tijeras.

[metáfora] El *tijeretazo* del gobierno de Artur Mas (CiU) afecta ya a todos los recursos de la sanidad catalana: los hospitales mantienen cerradas el $25 \%$ de las

\footnotetext{
${ }^{27}$ Diccionario de neologismos on line [www.upf.edu]
} 
camas y operatorios, unos 40 ambulatorios están cerrados desde verano mientras otra cincuentena recortado el servicio de atención nocturna, se ha reducido alrededor del $10 \%$ del servicio de transporte sanitario y se ha prescindido de los empleados eventuales que acababan contrato. $\mathrm{N}, \mathrm{N}, 4$, neologismo semántico [EP, 32, 06/01/2012]

travestir.

[DRAE] travestir 1. tr. Vestir a alguien con la ropa del sexo contrario. U. m. c. prnl.

[metáfora] Muchos profesores no cuentan para sus nuevas clases con ordenador con más materiales que el viejo libro de texto *travestido* de pantalla. [LV, 21/02/2011]

\section{volatilización}

[DRAE] volatilizarse. (De volátil). 1. prnl. Dicho de una sustancia: Transformarse espontáneamente en vapor.

[metáfora o analogía por el resultado] Incluso en la zona intocable de la economía, no parece exactamente lo mismo rebelarse contra una izquierda incapaz de frenar la *volatilización* del Estado que espantarse ante una derecha que fomenta su desborlamiento como programa implícito. [EP, 27/09/2011, OPIN, 27, 04/01/2012 ]

De los datos obtenidos se colige que la mayoría de los neologismos semánticos que recoge BOBNEO en el último año no responden a una necesidad denominativa objetiva, sino que son creaciones léxicas de carácter expresivo. No obstante, si nos fijamos en el tipo de neologismos semánticos obtenidos la mayor parte pertenecen a la lengua general, pero también, aunque en menor número, encontramos algunos neologismos semánticos en secciones concretas del periódico como puede ser el deporte (búnker, definir, galáctico, descarrilamiento, ungir, finalizador, galáctico, peinar, derecha, ensaladera); el mundo del motor (versión ecológica, habitabilidad, hábitat, teloneros, taper); de la economía (bit, burbuja, economía dópele, hucha, hundir, implosión, mochila, pista de aterrizaje, rating, suelo, techo, barril brent ); de la política (desnatado, tijeretazo); de la informática y la tecnología (parche, roque, tableta).

\section{CONCLUSIONES}

Después del análisis realizado podemos concluir lo siguiente atendiendo a las dos partes del trabajo:

En cuanto a las marcas de transición semántica empleadas en los diccionarios del español, se observa que ha habido una eliminación drástica a partir del 2000, aunque se sigue aplicando este tipo de marcación de una manera irregular y asistemática dentro de una misma obra o respecto a una misma unidad, si comparamos obras lexicográficas distintas.

A partir del análisis de las principales marcas valorativas de uso que se utilizan en los diccionarios para indicar las relaciones semánticas entre los diferentes significados de una entrada, hemos podido ver que se registran las ampliaciones de significado, mediante la etiqueta por extensión; las restricciones de significado, utilizando especialmente; y los cambios de significado por semejanza con la valoración por analogía, por metáfora, con la marca figurado, pero también hemos visto que la delimitación de estas transiciones o 
desplazamientos semánticos no es lo suficientemente clara. No obstante, no creemos que la solución sea eliminar dichas etiquetas, especialmente la de figurado, pues en nuestra opinión aportan información importante al usuario acerca del uso de dicha unidad, aunque sí sería necesario incluir un ejemplo para comprobar dicho empleo.

En cuanto a los resultados obtenidos en BOBNEO, se observa que la mayoría de los neologismos semánticos pertenecen a la lengua general, pero también hay un número considerable en los que se produce una especialización del significado entrando a formar parte de un ámbito especializado. Asimismo, según el análisis realizado un importante número de estas voces son nombres propios, principalmente de marcas registradas, que pasan a nombres comunes.

\section{REFERENCIAS BIBLIOGRÁFICAS}

ALMELA, Ramón (1999): Procedimientos de formación de palabras en español, Barcelona, Ariel.

Alvar EZQuerra, Manuel (1994): La formación de palabras en español, Madrid, Arco/Libros.

BAStuJi, J. (1979): «Notes sur la creativite lexicale», Neologie et lexicologie. Hommage a Louis Guilbert, Paris, Larousse, pp. 12-20.

BATTANER, Paz (2010): «La marca figurado como marca de uso», en Elisenda Bernal, Sergi Torner y Janet DeCesaris, ed., Estudis de lexicografia 2003-2005, Barcelona, Institut Universitari de Lingüística Aplicada, Universitat Pompeu Fabra, pp. 39-60.

- et. al. (2001): LEMA. Diccionario de la lengua española, Barcelona, Vox.

BlanK, A. (1999): «Co-presence and Succession. A cognitive Typology of Metonymy», en Klaus-Uwe Panther y Gunter Radden, eds., Metonymy in Language and Thought. Amsterdam-Philadelphia, John Benjamins Publishing Company, pp. 169-191.

BORRÀS, Laura y Sergi TORNER (2006): «De nuevo sobre la marca figurado en los diccionarios», en Elisenda Bernal y Janet DeCesaris, eds., Palabra por palabra: estudios ofrecidos a Paz Battaner, Barcelona, Institut Universitari de Lingüística Aplicada, Universitat Pompeu Fabra, pp. 33-45.

BosQue, Ignacio (1999): «El nombre común», en Ignacio Bosque y Violeta Demonte, dir., Gramática descriptiva de la lengua española, Madrid, Espasa-Calpe, pp. 3-76.

- y Violeta DEMONTE, dir. (1999): Gramática descriptiva de la lengua española, Madrid, Espasa-Calpe.

CABRÉ, Teresa (2009): «La classificació dels neologismes: una tasca complexa», en M. T. Cabré y Rosa Estopà, eds., Les paraules noves, Barceola, Eumo Editorial, pp. 10-37.

CoseriU, Eugenio (1977): Principios de semántica estructural, Madrid, Gredos.

DE Hoyos, José Carlos (1999-2000): «La marca de transición semántica: sentido figurado», Revista de lexicografía, VI, pp. 73-105.

FAJARDO, Alejandro (1996-1997): «Las marcas lexicográficas: concepto y aplicación práctica en la Lexicografía española», Revista de Lexicografía, III, pp. 31-57.

Feliu, Judit, Lídia MARTínez, H. Rosabel SAlazAR y Bàrbara TADEO (2009): «Els neologismes formats per resemantització», en $\mathrm{M}^{\mathrm{a}}$ Teresa Cabré y Rosa Estopà, eds.: Les paraules noves, Barcelona, Eumo Editorial, pp. 91-110. 
GonZÁlez PÉREZ, Rosario (2000-2001): «La marca figurado en los diccionarios de uso», Revista de lexicografía, VII, pp. 77-90

Guerrero RAmos, Gloria (1995): Neologismos en el español actual, Madrid, Arco/Libros.

GUILBERT, L. (1975): La creativite lexicale, Paris, Larousse Universite.

LANG, Mervyn F. (1992): Formación de palabras en español, Madrid, Cátedra

MARTÍNEZ GAJARDO, Constanza (2011): «Revisión crítico-bibliográfica en torno a la marca fig. en diccionarios de uso del español», Boletín de Filología, XLVI, 2, pp. 219-234

MATORE, Georges (1952): «Le neologisme: naissance et diffusion», Le francais moderne, 2, pp. 87-92.

Moliner, María (2008): Diccionario de uso del español, Madrid, Gredos, $3^{\mathrm{a}}$ ed. (CDROM).

OBSERVATORI DE NEOLOGIA (2004): «Neologia semàntica», en Llengua catalana i neología, Barcelona, Meteora, pp. 192-217.

- (2004): Metodologia del trabajo en neologia: criterios, materiales y procesos, Barcelona, Institut Universitari de Linguistica Aplicada, Universitat Pompeu Fabra. [Version digital: http://www.iula.upf.edu/repositori/].

OLIMPIO DE O. SILVA, Ma Eugénia(2013): «Las marcas de transición semántica en el tratamiento de las locuciones verbales», en http://www.biblioteca.org.ar/libros/141104.pdf, pp. 844-849.

PÉREZ CASTRO, Luis Carlos (2002): «Acerca de los usos y sentidos figurados y de su tratamiento lexicográfico», Revista española de lingüística, 32, 1, pp. 123-128.

Porto Dapena, José-Álvaro (2002): Manual de técnica lexicográfica, Madrid, Arco/libros

ReAl ACADEMIA EsPañola (2001): Diccionario de la Lengua Española, Madrid, Espasa Calpe $\left(21^{\mathrm{a}}\right.$ ed.).

- (2010): Nueva Gramática de la Lengua española, Madrid, Espasa.

REY, Alain (1976): «Neologisme: un pseudo-concept?», Cahiers de lexicologie, 28, 1, pp. 3-17.

RoJAS, Darío (2010): El tratamiento de la polisemia léxica regular y las facetas en una muestra de diccionarios monolingües de español, Tesis para optar al grado de Magíster en Lingüística con mención Lengua Española, Universidad de Chile. [En línea] Disponible en http://www.cybertesis.uchile.cl/tesis/uchile/2010/fi-rojas_da/html/index.html [Consulta 28/09/2012]

SABrayrolles, J.F. (1997): «Neologismes: Une typologie des typologies», Cahier du CIEL, pp. 11-48.

SÁNCHEZ MANZANARES, Carmen (2009): «Procedimientos trópicos en la neología semántica: sistematicidad y creatividad», Revista de Investigación Lingüística, 12, pp. 123-146.

- (2006): Creación lingüística: la renovación del léxico del español actual por la metonimia, Tesis Doctoral, Murcia, Universidad de Murcia, http://www.tesisenred.net/TDR-0928106-125044/index_cs.html.

SANTAMARÍA PÉREZ, María Isabel (2011): «Entre la Pragmática y la Lexicografía: la marca humorístico en los diccionarios monolingües de aprendizaje del español», Revista de lexicografia, XVII, pp. 179-208.

- (2013): "La neología terminológica de tipo semántico en el español actual", LEA: Lingüística española actual, 35, 2, pp. 241-274.

SECO, Manuel (1978): «Problemas formales de la definición», en Estudios de lexicografía española, Madrid, Paraninfo, pp. 15-34. 
Olimpia ANDRÉS y Gerardo RAMOs (1999): Diccionario del español actual (DEA), Madrid, Aguilar, 2 vols.

STEFFENS, María y Esther BAIWIR (2009): «Neología semántica y polisemia: el caso del truncamiento», Revista de Investigación Lingüística, pp. 175-184.

Ullmann, S. (1965): Introduccion a la Semantica francesa, Madrid, Publicaciones de la Revista de Filologia Espanola, XV.

VAN DER MEER, G. (1999): «Metaphors and dictionaries: The morass of meaning, or how to get two ideas for one», International Journal of Lexicography, 12, 3, pp. 195-208.

VARELA, Soledad, ed. (1993): Fundamentos de morfología, Madrid, Síntesis.

VARó VARÓ, Carmen, Tadea DíEz Hormigo, Tady Ma Jesús PAREdes DuARTE (2009): «Modelos comunicativos y producción e interpretación», Revista de Investigación Lingüistica, 12, pp. 185-216. 